\title{
Psychiatric beds attached to a community mental health centre
}

\author{
Jed Boardman, Richard Hodgson and Martyn Lewis
}

\begin{abstract}
The loss of poychlatilic beds assoclated with the closure of large peychiatric institutions creates problems for the community care of those with severe mental illness. This paper describes the use and posslble advantages of a non-acute in-patient unit affached to a Community Mental Health Centre in North Stafiordahire which has priortibed individuats with severe mental illness.
\end{abstract}

The general psychiatric services for younger adults in North Staffordshire Health District (population 471619 ) are divided into six geographical sectors. In January 1992, two new purpose built Community Mental Health Centres opened in two of these sectors. Attached to each centre was an eight bed in-patient unit. This paper describes the use of one of these in-patient units (the 'Bungalow') at Lyme Brook Mental Health Centre.

\section{Lyme Brook Mental Health Centre}

Lyme Brook Mental Health Centre (LBMHC) provides the base for the adult (15-65 years) community psychiatric services for the population to the north and west of Newcastle-underLyme. The population consists of 74000 individuals representing a predominantly white working class and the area has an average Jarman index of -0.4. LBMHC houses a multidisciplinary team of nurses, CPNs, doctors, occupational therapists, social workers and a clinical psychologist. It provides out-patient, assessment, day and non-acute in-patient facilities for the sector. Acute in-patient beds are housed at the DGH which is about 3 miles from LBMHC. There are 10 acute beds for the area covered by the centre.

The Bungalow is a single storey building which is attached to the main body of the centre. It has eight single bedrooms, with communal bathrooms, kitchen and living room. It provides a homely environment for the residents where they are encouraged to be as independent as possible, shopping for themselves and making their own meals. The Bungalow is staffed over 24 hours with two nurses on duty at any one time. Medical cover is provided by a clinical assistant and senior registrar. The staff for the Bungalow also cover the day and assessment facilities at
LBMHC and are not dedicated specifically to the in-patient unit. A daily programme is arranged for all residents but they may also participate in day facility activities.

The Bungalow does not provide any acute inpatient services. In practice four types of admission are accepted:

- Predischarge admissions. Transfer of patients from the acute ward as they are recovering from the acute phase of their illness.

- Assessment/rehabilitation admissions. Patients who are not acutely ill but may require in-patient assessment or short-term rehabilitation.

- Crisis prevention admissions. Individuals known to the service for whom an admission may be necessary to prevent deterioration of their condition or a crisis occurring.

- Respite admissions.

The Bungalow cannot accept patients who require a high level of nursing or medical input such as those who are disturbed and require more than general nursing observation or those who require physical nursing care. Patients on a section of the Mental Health Act are accepted. In principle all other patients are accepted but emphasis is placed on those with long-term severe mental illnesses. If patients deteriorate while in the Bungalow arrangements can be readily made to transfer them to the acute ward. There is no on-site medical cover after $5.00 \mathrm{pm}$ or at weekends and at these times this is provided by the consultant on-call for the district.

Length of stay can vary but up to 3 months is acceptable. Respite admissions are arranged for 1-2 weeks.

\section{The first 3 years}

The Bungalow took its first admissions in November 1992 and up to the end of December 1995, had 210 admissions consisting of 106 individuals. Over half $(56.6 \%)$ of the individuals were female, $52 \%$ aged less than 40 years and $32 \%$ aged over 50 years (mean age 41 years). Forty-two per cent were married, $21.7 \%$ 
divorced, separated or widowed and only $8.4 \%$ were in employment. The largest single diagnostic group was schizophrenia and $65 \%$ of all individuals admitted had a functional psychosis (Table 1).

The majority had past contact with psychiatric services, although for a fifth the admission represented their first episode of contact with psychiatric services. Almost half had already had contact with the services at Lyme Brook and almost $60 \%$ had had a previous acute admission under the present consultant.

Over half the admissions were directly to the Bungalow but transfer from the acute ward was the commonest route of admission (Table 1). The majority of admissions lasted for less than 4 weeks, but the length of admission depended on the reason for admission. Mean admission length of those transferred from the acute ward was 48 days, for rehabilitation/assessment 41 days, crisis prevention 21 days and respite 9 days.

Twelve $(5.7 \%)$ of the discharges from the Bungalow were not followed up at LBMHC: two were referred to psychiatrists out of the district, three were referred to other psychiatrists in North Staffordshire and seven referred back entirely to the care of their GP. Fifteen of the

Table 1. Admissions to Lyme Brook Bungalow. November 1992-end December 1995

\begin{tabular}{|c|c|}
\hline $\begin{array}{l}\text { a) Inclividuals (inst over admission to } \\
\text { Bungalow) }(n=106)\end{array}$ & \\
\hline $\begin{array}{l}\text { Diagnoels (ICD-10) } \\
\text { Schizophrenia (F20, 25) } \\
\text { Paranold psychoses (F22, 23) } \\
\text { Blpolar affectlve (F30, 31) } \\
\text { Psychotic depression (F32.3) } \\
\text { Depression (F32, 33) } \\
\text { Anxlety disorders (F41) } \\
\text { Adjustment disorders (F43) } \\
\text { Personality disorders (F60) } \\
\text { Others }\end{array}$ & \begin{tabular}{r}
\multicolumn{1}{c}{$\%$} \\
45.3 \\
3.8 \\
12.3 \\
3.8 \\
8.5 \\
6.6 \\
2.8 \\
10.4 \\
6.6
\end{tabular} \\
\hline Acute admisaton since 1991 & 59.4 \\
\hline Seen proviousty of LBMHC & 45.3 \\
\hline Past contact with poychiatic services & 78.3 \\
\hline \multicolumn{2}{|l|}{ b) All odmisatons ( $n=210)$} \\
\hline $\begin{array}{l}\text { Reason for admisalon } \\
\text { Transfer from aculte ward } \\
\text { Assessment/rehabilltation } \\
\text { Crisis prevention } \\
\text { Resplte }\end{array}$ & $\begin{array}{l}41.9 \\
18.1 \\
10.5 \\
29.5\end{array}$ \\
\hline 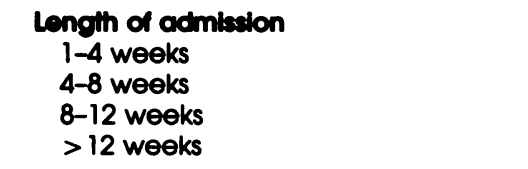 & $\begin{array}{r}64.3 \\
15.4 \\
11.5 \\
8.2\end{array}$ \\
\hline
\end{tabular}

210 admissions needed transfer to the acute ward during their stay and 13 of these were subsequently transferred back to the Bungalow. Two patients became physically ill during their admission and required transfer to a medical ward. Almost all discharges (94.3\%) had some form of follow-up from the services at Lyme Brook.

\section{Overview}

While there are examples of in-patient units which are not attached to hospital sites (Sensky \& Scott, 1995) it is believed that the Bungalow and its equivalent in another sector are the only ones of their type in the country. The service provided is currently being evaluated using a longitudinal design and results will not be available until 1997. However, the experience assessed during the first three years suggests that such a facility has several benefits.

North Staffordshire district has only 94 acute beds for a total population of 471619 (19.9 per 100000 population). The avallability of additional non-acute beds means that patients can be moved from the acute ward into a homely environment as they are recovering and thus ease congestion on the acute wards.

Transfer from the acute ward means that the patients can have a period of further assessment and rehabilitation as they are recovering from the acute phase of their illness. Arranging for this in a unit dedicated to this purpose means that patients can get appropriate attention as staff are not distracted by acute admissions and crises.

The non-acute beds are part of the facilities that will offer the follow-up for the patients. This means that during their in-patient stay the patients will be introduced to the services and individuals which will be part of other after-care arrangements. This has the potential to increase the likelihood of successful participation in services and is in the spirit of the Care Programme Approach and Section 117 arrangements.

Other patients who may require periods of inpatient intervention or assessment or need respite can be admitted directly to the beds. An acute in-patient ward may not be suitable for such patients and they may refuse such an admission. The non-acute beds can increase the scope and quality of in-patient facilities offered to patients.

The Bungalow offers pleasant surroundings which are acceptable to patients and their families. Such patient satisfaction with inpatient services can increase compliance and the chances of successful follow-up and outcome. 
There have been a number of indirect benefits of attaching the in-patient unit to the community mental health centre. The fact that the unit is staffed 24 hours a day for 7 days a week means that the staff can be available to support day and out-patients and their relatives outside of usual working hours. Most of this support and advice is given over the telephone but it has also been possible to support more vulnerable patients in person at weekends and Bank Holidays and prevent likely admissions. In addition the nursing staff can also see some of their individual out-patients for arranged appointments after $5.00 \mathrm{pm}$ or at weekends thus increasing the range and flexibility of the services offered at LBMHC.

The Bungalow is one part of a range of facilities designed to offer integrated general psychiatric care to younger adults in a sector of the population in North Staffordshire. It is one of two examples of such a local facility. Other such facilities are planned and it is hoped that there will be one such unit in each of the six sectors in the district in the future. Experience of the inpatient unit over three years suggests that it is a useful addition to community based facilities and can offer a means by which services can be prioritised for those with long-term and severe mental illnesses and aftercare can be improved.

\section{Reference}

SENSKY, T. \& SCOTT, J. (1995) Acute inpatient wards. In Emergency Mental Health Services in the Community (eds. M. Phelan, G. Strathdee and G. Thornicroft). pp. 320-339. Cambridge: Cambridge Untversity Press.

* Jed Boardman, Senior Lecturer in Social Psychiatry; Richard Hodgson, Senior Clinical Lecturer; and Martyn Lewis, Research Assistant, Academic Department of Psychiatry. School of Postgraduate Medicine, Keele University, Thormburrow Drive, Stoke-on-Trent, Staffs ST4 $7 Q B$

*Correspondence 